\title{
Perceptions and acceptance of telemedicine among medical oncologists before and during the COVID-19 pandemic in Turkey
}

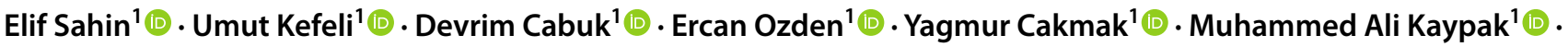 \\ Mustafa Seyyar ${ }^{1}$ (D) Kazım Uygun ${ }^{1}$ (i)
}

Received: 9 December 2020 / Accepted: 9 May 2021 / Published online: 7 June 2021

(c) The Author(s), under exclusive licence to Springer-Verlag GmbH Germany, part of Springer Nature 2021

\begin{abstract}
Background As a result of technological developments in healthcare services, telemedicine is becoming widespread. We aimed to determine the effect of COVID-19 on Turkish medical oncologists' opinions of telemedicine through a survey. Methods This study was conducted using an online questionnaire linked to an invitation e-mail sent to the members of the Turkish Medical Oncology Association mailing group between May and July 2020.

Results Of the 110 ( 73 males and 37 females) medical oncologists who answered the questionnaire, the average age was $43.9 \pm 7.29$ (range: $31-64$ ) years, and the majority of the respondents were academics. The most commonly used telemedicine method was store and forward (69.7\%). Telemedicine use during clinical visits and multidisciplinary councils increased significantly during the COVID-19 pandemic ( $p<0.001$ in both cases).

Conclusion The use of telemedicine increased during the COVID-19 pandemic, and the pandemic has led oncologists to view telemedicine more positively.
\end{abstract}

Keywords Telemedicine $\cdot$ Telehealth $\cdot$ Teleoncology $\cdot$ Medical oncology $\cdot$ Cancer

Elif Sahin

dr_elifsahin48@hotmail.com

Umut Kefeli

ukefeli@yahoo.com

Devrim Cabuk

devrim.cabuk@kocaeli.edu.tr

Ercan Ozden

ercanozden@hotmail.com

Yagmur Cakmak

dr.ygmr@gmail.com

Muhammed Ali Kaypak

m.alikypk@gmail.com

Mustafa Seyyar

mustafaseyyar27@hotmail.com

Kazım Uygun

kzuygun@hotmail.com

1 Faculty of Medicine, Department of Medical Oncology, Kocaeli University, Kocaeli 41000, Turkey

\section{Introduction}

In recent years, the use of technology has increased in healthcare services, as in many other fields. Telemedicine is the transfer of medical information for the diagnosis, prevention, treatment, and follow-up of diseases or for educational purposes using information and telecommunication technology (ICT) [1]. The application of telemedicine to oncology is called teleoncology [2].

Telemedicine practice is examined in three categories: store and forward, remote control, and interactive telemedicine. However, a combination of these practices can also be applied [3]. The store and forward method is also called asynchronous telemedicine. Patient data, such as medical history, laboratory and pathology reports, and radiological imagings, are collected by a patient or a doctor and then sent to a specialist for diagnosis and treatment planning [4]. Remote control is applied by healthcare professionals for the continuous monitoring of patients' vital signs or parameters related to chronic disease. This type of monitoring is often used for the management of high-risk patients, for instance, patients who have recently been hospitalized with cardiac disease, chronic obstructive pulmonary disease, or diabetes 
mellitus [5, 6]. Interactive telemedicine allows for a meeting and a subsequent discussion between a patient and a doctor or a doctor and another doctor through videoconferencing programs, similar to face-to-face meeting, allowing to see the other person's gestures and facial expressions in real time. However, it is not necessary to be in the same place [7].

Cancer is the second cause of death in the world and about $70 \%$ of deaths from cancer occur in low and middleincome countries [8]. In these countries, it is anticipated that the number of oncologists is low and it is difficult to access other physicians who will refer to an oncologist or other health services. In addition, transportation to hospital can be difficult due to geographical and economic reasons. Telemedicine can reduce inequality in this issue. For example, a patient living in a rural area can get advice from a doctor in a remote city or country. If there is fast and stable internet access, doctors in individual cities can discuss the patient among themselves and decide on his/her treatment in an online council. It may provide earlier diagnosis and treatment by providing more convenient access to oncologists, especially in low and middle-income countries. In addition, telemedicine both lowers transportation costs for patients and reduces hospitalizations [9]. Telemedicine and telehealth will contribute not only to meeting with the oncologist, but also getting psychological support and solving other health problems without leaving home. Thus, it can improve the quality of life of patients with cancer [10,11]. However, telemedicine also has disadvantages such as lack of intimacy and technical difficulties [12].

The coronavirus disease 2019 (COVID-19) pandemic has caused many changes in healthcare services worldwide. For example, most of the elective surgical operations were postponed, some routine screenings were postponed, the number of patients seen in clinics per day was reduced, some retired healthcare personnels returned to duty, and some healthcare personnels were assigned to pandemic clinics different from their specialties $[13,14]$. The acceleration of the increase in telemedicine usage was also one of these changes $[15,16]$.

In this article, we aim to evaluate the opinions and experiences of medical oncologists concerning telemedicine and analyze the changes in the use of telemedicine during the COVID-19 pandemic in Turkey through a questionnaire.

\section{Materials and methods}

This cross-sectional study used an online questionnaire to collect data from medical oncologists working in Turkey. The questionnaire, conducted between May and July 2020, was sent to the members of the "Turkish Medical Oncology Association" mail group through an invitation e-mail. This e-mail included information about telemedicine, study content, and the survey, followed by a link to an online survey form [17]. Google Surveys, which allows respondents to answer anonymously, was employed. The responses of the respondents were analyzed.

"Turkish Medical Oncology Association" is an association of 782 medical oncologists. One hundred seventeen of the members are professors, 175 are associate professors, 27 are assistant professors, 206 are experts, and 197 are fellows. It helps medical oncologists in Turkey to communicate with each other and find solutions to their problems. It has aims such as supporting scientific studies and contributing to the education of fellows. More than $90 \%$ of medical oncologists in Turkey is a member of the Turkish Medical Oncology Association.

The questionnaire was based on articles about telemedicine [18-20] and the experience of the authors' daily practice. Medical oncologists were asked to evaluate their institutions' current telemedicine practices and then answer questions about telemedicine based on their experience and opinions (if they did not have experience). Survey questions were organized in a multiple choice format, and only one option could be selected. Categorical data obtained from the respondents were utilized to provide an overview of the telemedicine process and its challenges.

In Turkey, during the pandemic period, telemedicine meetings have been started in some hospitals routinely by the decision of the hospital management institutionally. On the other hand, some physicians used telemedicine personally for some patients, while there was no telemedicine examination in their institutions. Therefore, questions about the use of telemedicine in the questionnaire were asked twice. The first one is "was it applied in the institution/hospital?"; the second is "..... did you use it personally?".

The study protocol was approved by the Kocaeli University Clinical Research Ethics Committee (KOU GOKAEK 2020/133).

All statistical analyses were performed using IBM SPSS for Windows version 20.0 (SPSS, Chicago, IL, USA). Kolmogorov-Smirnov and Shapiro Wilk's tests were used to assess the assumption of normality. Continuous variables were expressed as mean \pm standard deviation and median (25th-75th percentile). Categorical variables were summarized as counts (percentages). Comparisons of continuous variables between groups were performed using the Mann-Whitney $U$ test since the normality assumption did not hold. Chi-square test was used to determine relationships between categorical variables. McNemar's test and the marginal homogeneity test were applied to determine changes in respondents' answers. Two-sided $p$ value $<0.05$ was considered statistically significant. 


\section{Results}

The number of medical oncologists who answered the questionnaire was $110,66.4 \%$ of whom were men. The average age of the participants was $43.9 \pm 7.29$ ( $\min , 31$; max, 64) years. The majority of the respondents were professors, seeing 20-40 patients a day, working at the university hospital, and had been employed for longer than 10 years in oncology. The profiles of the doctors participating in our survey are summarized in Table 1.

The median age of telemedicine users was 40 before the pandemic and 43 during the pandemic. Before and during the pandemic, no difference was found when telemedicine users were compared by age ( $p=0.339, p=0.819$, respectively). Nine (53\%) of 17 clinicians who used telemedicine before the pandemic and 34 (69\%) of 49 clinicians who used

Table 1 Details about the oncologists participating in our survey

\begin{tabular}{|c|c|}
\hline Doctors' characteristics & $\mathrm{N}=110$ \\
\hline Age (years) & $43.9 \pm 7.29$ \\
\hline Male $(\%)$ & $73(66 \%)$ \\
\hline \multicolumn{2}{|l|}{ Academic title (\%) } \\
\hline - Professor & - $31(28 \%)$ \\
\hline - Associate professor & - $36(33 \%)$ \\
\hline - Assistant professor & - $4(4 \%)$ \\
\hline - Specialist & - $27(25 \%)$ \\
\hline - Fellow & - $11(10 \%)$ \\
\hline \multicolumn{2}{|l|}{ Work institution (\%) } \\
\hline - University hospital & - $46(42 \%)$ \\
\hline - Education research hospital & - $20(18 \%)$ \\
\hline - Private hospital & - $38(35 \%)$ \\
\hline - Public hospital & • $4(4 \%)$ \\
\hline - Private clinic (individual) & - $2(2 \%)$ \\
\hline \multicolumn{2}{|l|}{ Years in practice $(\%)$} \\
\hline$\bullet<10$ years & - $52(48 \%)$ \\
\hline - $10-20$ years & - $45(41 \%)$ \\
\hline$\bullet>20$ years & - $12(11 \%)$ \\
\hline \multicolumn{2}{|l|}{ Number of patients examined per day (\%) } \\
\hline$\bullet<20$ patients & - $28(26 \%)$ \\
\hline - 20-40 patients & - $46(42 \%)$ \\
\hline - 40 patients & - $36(33 \%)$ \\
\hline \multicolumn{2}{|c|}{ Which program do you prefer most in telemedicine? (\%) } \\
\hline - WhatsApp & • $71(69 \%)$ \\
\hline - Skype & - $5(5 \%)$ \\
\hline • Zoom & $\bullet 11(11 \%)$ \\
\hline - Other & - $16(15 \%)$ \\
\hline \multicolumn{2}{|c|}{ Which method do you use in examination via telemedicine } \\
\hline - Store and forward & • $69(69 \%)$ \\
\hline - Interactive telemedicine (video conference) & - $30(30 \%)$ \\
\hline - Remote Control & - $1(1 \%)$ \\
\hline
\end{tabular}

telemedicine during the pandemic were male. There was no difference between telemedicine users before and during the pandemic by gender ( $p=0.299, p=1.0$, respectively).

It was observed that the method clinicians used most frequently to contact patients was store and forward (69.7\%), and the program used most often was WhatsApp Messenger $(68.9 \%)$.

A physical examination includes the inspection, palpation, percussion, and auscultation. However, a doctor can only do inspection in a telemedicine visit and sometimes say the patient to palpate himself/herself. But doing percussion and auscultation are impossible in telemedicine for now. In the survey, when the participants were asked whether failure to perform a full physical examination would cause a fatal error in the follow-up of a cancer patient, 60 (59\%) respondents answered "rarely," and 34 (34\%) answered "usually."

According to $52.5 \%$ of the participants, the examinations using telemedicine took less time than those performed in the clinic, while $30.3 \%$ stated that the examinations took longer. According to $42.4 \%$ of oncologists, the follow-up frequency of the patients does not change with telemedicine visits. On the other hand, $31.3 \%$ think that the frequency of follow-up has increased and $26.3 \%$ think decreased. The answers given by the participants to other questions about telemedicine are summarized in Table 2.

During the COVID-19 outbreak, the utilization of telemedicine in the examination of patients increased significantly in our study group. This increase occurred both as the personal preference of the clinicians and the choice of the hospital management ( $p<0.001$ in both cases). Similarly, there was a significant increase in multidisciplinary councils made with telemedicine $(p<0.001)$. The change in telemedicine use before and during the COVID-19 pandemic is summarized in Table 3.

\section{Discussion}

Telemedicine is the provision of health services to remote people through ICT [21]. During the COVID-19 pandemic, people were not able to leave their homes and were afraid of coming to the hospitals; therefore, the search for alternatives began for meeting the doctors. This situation has spread the use of telemedicine in oncology as well as in many clinics.

The use of telemedicine in oncology (also called teleoncology) began in 1990 with a study by Lipsedge et al. [22]. In this study, supportive care was provided to cancer patients through psychiatrists. In the following 30 years, a lot of study was done in this field. A literature review of all existing mobile technologies and integrated care studies focusing on cancer and cancer supportive care was published by Nasi et al. in 2015 [23]. This review revealed that mobile technologies are predominantly used for during the treatment of 
Table 2 The answers given by the participants to questions about telemedicine

\begin{tabular}{|c|c|c|c|c|}
\hline & $\begin{array}{l}\text { Always } \\
\text { n }(\%)\end{array}$ & $\begin{array}{l}\text { Usually } \\
\mathrm{n}(\%)\end{array}$ & $\begin{array}{l}\text { Rarely } \\
\mathrm{n}(\%)\end{array}$ & $\begin{array}{l}\text { Never } \\
\mathrm{n}(\%)\end{array}$ \\
\hline \multicolumn{5}{|l|}{ - During telemedicine visits: } \\
\hline Are you in the same place compared to your clinic exams? & $30(30 \%)$ & $43(43 \%)$ & $16(16 \%)$ & $11(11 \%)$ \\
\hline Do you want to see the patient again in the clinic exam? & $4(4 \%)$ & $62(62 \%)$ & $34(34 \%)$ & $0(0 \%)$ \\
\hline Is your meeting interrupted? & $5(\% 5)$ & $39(39 \%)$ & $53(54 \%)$ & $2(2 \%)$ \\
\hline $\begin{array}{l}\text { Does interruption of your meeting reduce your concentration and the efficiency of the } \\
\text { visit? }\end{array}$ & $20(20 \%)$ & $48(48 \%)$ & $32(32 \%)$ & $0(0 \%)$ \\
\hline Do you think patients express themselves sufficiently? & $3(3 \%)$ & $68(67 \%)$ & $29(29 \%)$ & $1(1 \%)$ \\
\hline Do you think you express yourself sufficiently? & $9(9 \%)$ & $71(70 \%)$ & $20(20 \%)$ & $1(1 \%)$ \\
\hline Do you think patients are satisfied? & $3(3 \%)$ & $68(67 \%)$ & $30(30 \%)$ & $0(0 \%)$ \\
\hline Do you think you are satisfied? & $1(\% 1)$ & $49(48 \%)$ & $41(41 \%)$ & $10(10 \%)$ \\
\hline $\begin{array}{l}\text { Would failure to full physical examination lead to a fatal error in the follow-up of a } \\
\text { patient with cancer? }\end{array}$ & $6(6 \%)$ & $34(34 \%)$ & $60(59 \%)$ & $1(1 \%)$ \\
\hline Do you think that multidisciplinary councils with telemedicine are efficient? & $13(12 \%)$ & $65(59 \%)$ & $31(28 \%)$ & $1(1 \%)$ \\
\hline $\begin{array}{l}\text { - Before the COVID-19 pandemic, did you believe that examinations with telemedicine } \\
\text { can be performed in Medical Oncology? }\end{array}$ & $3(3 \%)$ & $18(18 \%)$ & $25(25 \%)$ & $54(54 \%)$ \\
\hline $\begin{array}{l}\text { - During the COVID-19 pandemic, do you believe that examinations with telemedicine } \\
\text { can be performed in Medical Oncology? }\end{array}$ & $4(4 \%)$ & $57(56 \%) 57(56 \%)$ & $35(35 \%)$ & $5(5 \%)$ \\
\hline $\begin{array}{l}\text { - After the Covid-19 pandemic, do you think that examinations in Medical Oncology will } \\
\text { be performed with telemedicine? }\end{array}$ & $3(3 \%)$ & $27(27 \%)$ & $62(61 \%)$ & $9(9 \%)$ \\
\hline $\begin{array}{l}\text { - In the future, if the speed of the internet increases and the use of the internet of things } \\
\text { and augmented reality become widespread and optimally used, can the visits in Medical } \\
\text { Oncology be performed with telemedicine? }\end{array}$ & $4(4 \%)$ & $38(38 \%)$ & $54(53 \%)$ & $6(6 \%)$ \\
\hline
\end{tabular}

patients, but used less frequently in prevention, diagnosis, decision-making, and follow-up stages. Our study has shown that telemedicine use has increased significantly, both personally and institutionally, during the COVID-19 outbreak $(\mathrm{p}<0.001)$ (see Table 3). Participants thought that the telemedicine visits would continue even if decreased partially in the post pandemic period. These results suggest that some physicians who see the convenience and other advantages of using telemedicine and get used to these visits will continue to meet with patients via telemedicine.

In Turkey, chemotherapy with teleoncology has not been applied to the patients in rural areas yet. However, studies on this subject in some countries have yielded positive results $[24,25]$. In these studies, a health institution is established in rural areas, and chemotherapy nurses and trained personnel are assigned. Oncologists in the city center meet with patients living in rural areas via telemedicine and plan the chemotherapy, and then the patients receive their treatment where they live. In these studies, patients were given commonly used chemotherapy regimens, and it was observed that there was no difference between the chemotherapy tolerance of the patients. Besides, a better quality of life results was found in patients, and it was revealed that less cost and time were spent. We think that these telemedicine meetings can also be used for cancer patients who need palliative support in oncology.

According to the survey results, after the pandemic, decision-making multidisciplinary tumor councils have started to be made via telemedicine in Turkey. There was a significant difference between before and after the pandemic in terms of conducting multidisciplinary councils through telemedicine $(p<0.001)$. In a prospective pilot study on multidisciplinary
Table 3 The change in telemedicine use before and during the COVID-19 pandemic

\begin{tabular}{llll}
\hline & $\begin{array}{l}\text { Before the pandemic } \\
\text { (n) [\%] }\end{array}$ & $\begin{array}{l}\text { During the pandemic } \\
\text { (n) [\%] }\end{array}$ & $p$ Value \\
\hline $\begin{array}{l}\text { Using telemedicine institutionally (choice of the } \\
\text { hospital management) }\end{array}$ & $10(9 \%)$ & $56(51 \%)$ & $p<0.001$ \\
$\begin{array}{l}\text { Using telemedicine personally by clinicians } \\
\text { - Male }\end{array}$ & $17(15 \%$ & $49(45 \%)$ & $\mathrm{p}<0.001$ \\
- Median age & $\bullet 9(8 \%)$ & $\bullet 34(31 \%)$ & \\
Council meetings by telemedicine & $\bullet 40$ & $\bullet 43$ & $p<0.001$ \\
\hline
\end{tabular}


tumor councils [26], it was found that the meetings held by the videoconferencing method were not distinctly different from the routine tumor discussion councils and that the participants had confidence and satisfaction in these conferences. Similarly in our study, $70 \%$ of responders said that they always or usually found these multidisciplinary meetings useful. As a result of the telemedicine councils, physicians can exchange information with each other anywhere and at any time. Thus, it is possible to exchange information easily even among physicians in different cities and countries. In the future, this may contribute to the increase of intercity and international case discussions.

The most used program by the clinicians in our study to communicate with patients was WhatsApp Messenger $(68.9 \%)$, while the most used telemedicine method was store and forward (69.7\%). Messaging is used more widely in our routine lives, and it is easier for people to use the method they are used to. Besides, this method is easily accessible and allows doctors or patients to share information anywhere and anytime. However, with the pandemic process, video talk programs became widespread rapidly and entered our routine lives [27]. People who never or rarely used these types of programs started to use them. This situation can suggest that the use of interactive telemedicine will increase in the near future. In order to use the remote control method more frequently, technological developments and its integration into the health system need to be increased, and the financial burden on individuals and states should be reduced. In the near future, it may be possible to move telehealth services to a higher level with the combined use of all three telemedicine methods.

In our study, most of the clinicians stated that the telemedicine visits were shorter than the routine visits. In addition to the short visit time, telemedicine also saves the patient from coming to the hospital. Therefore, it can be said that telemedicine is a time-saving method especially for the patient. A study published by Russo et al. [28] confirmed this idea. In that study, it was found that telemedicine gave the patient an average of 145 miles and 142 min per visit.

Most of the medical oncologists in our study thought that doctors and patients could express themselves sufficiently in telemedicine meetings. Also $70 \%$ of the participants (who answer always and usually) stated that the patients and 50\% (who answer always and usually) stated the doctors were satisfied with the meetings via telemedicine. In a study conducted in India, $82 \%$ of patients and all doctors said that they were satisfied with telemedicine meetings. However, there were also participants who reported that they were uncomfortable with some technical problems, time-scheduling, or talking to the camera [19]. In teleoncology studies, it was revealed that patients and clinicians were generally satisfied [2]. However, some medical oncologists who answered our questionnaire stated that they thought telemedicine could cause communication problems between doctors and patients and could lead to fatal errors due to incomplete physical examination. Our study was intended only for clinicians, but some studies conducted on patients reported that patients have concerns about their privacy [23] [29]. It is known that there may be cybercrime in e-health services [30]. Considering these negative aspects, it can be said that telemedicine's legal ground is not sufficient and legal problems may occur. Therefore, governments must take measures against cybercrime. And there is a need to enact new laws or regulate existing laws on telemedicine to protect both the patient and the doctor. As these regulations are made, confidence in using telemedicine will increase, and this will contribute to the widespread use of telemedicine.

Various studies have shown that telemedicine and telehealth services can provide advantages such as ease of use, ease of access and communication with the service providers, low cost, and shortening of travel time. In these studies, it has been stated that telehealth provide contributions such as facilitating management of the disease and symptoms, increasing their education and treatment compliance, and reducing hospitalizations [31, 32]. But there is still not enough evidence to support the use of only telemedicine in examination of cancer patients. Even so, the use of telemedicine will increase as a result of technological advances. In the near future, it is predicted that internet of things and augmented reality will be used in many areas [33]. Although the idea that physicians can perform patient examinations remotely using these technologies seems utopian for now, the doctors who participated in our study think that these technologies can be integrated and used with telemedicine in the near future. However, since even small mistakes in the follow-up of patients with cancer can cause big problems, some oncologists still do not want to compromise face-to-face examination. It is seen that there is no complete trust and consensus on teleoncology. For now, it seems too early to say that telemedicine will completely replace face-to-face examination in oncology. Future studies could reduce the ambiguity on this matter by investigating the quality of exams conducted via telemedicine.

\section{Limitations}

This study includes only the opinions and experiences of medical oncologists in Turkey who responded to our survey. Since the questionnaire was prepared as an online questionnaire, it could not be tested whether the questions were understood or not (however, all questions from the participants were answered via e-mail). 


\section{Conclusion}

Although some medical oncologists resist the use of telemedicine, the COVID-19 pandemic has increased the use of telemedicine in medical oncologists in Turkey. Technical and legal advances are needed to expand the usage of telemedicine. After increasing the studies in this field, telemedicine can replace the majority of the routine policlinic visits in the future.

Authors' contributions Conception and design: Elif Sahin, Umut Kefeli. Provision of study materials: Elif Sahin, Umut Kefeli. Collection and assembly of data: Elif Sahin, Umut Kefeli. Writing original draft: Elif Sahin. Editing and finalized the manuscript: All authors.

Data availability The datasets generated during and/or analyzed during the current study are available from the corresponding author on reasonable request. To view our survey, visit https://docs.google.com/ forms/d/e/1FAIpQLScP8CFYoBz3RhrSGG7c2tmkAQx86uCsaSECN$7 \mathrm{gqT} 90 \mathrm{oZ} 9 \mathrm{EWg} / \mathrm{view}$ form $\mathrm{vc}=0 \& \mathrm{c}=0 \& \mathrm{w}=1$.

Code availability Not applicable.

\section{Declarations}

Ethics approval This study performed in line with the principles of the Declaration of Helsinki. The questionnaire and study protocol was approved by the Kocaeli University Clinical Research Ethics Committee (KOU GOKAEK 2020/133).

Consent to participate and consent for publication Before starting the online survey, a consent to participate in the study and permission to publish the results was requested by informing them. Those who gave this permission filled out the questionnaire.

Conflict of interest The authors declare no competing interests.

\section{References}

1. Ryu S (2012) Telemedicine: opportunities and developments in member states: report on the second global survey on eHealth 2009 (Global Observatory for eHealth Series, Volume 2). Healthc Inform Res 18(2):153. https://doi.org/10.4258/hir.2012. 18.2 .153

2. Olver I (2003) Telemedicine in oncology. Curr Probl Dermatol 32:121-126. https://doi.org/10.1159/000067385

3. Flodgren G, Rachas A, Aj F, Inzitari M, Shepperd S (2015) Interactive telemedicine : effects on professional practice and health care outcomes ( Review ) SUMMARY OF FINDINGS FOR THE MAIN COMPARISON. Cochrane Database Syst Rev Interact Art. No.(9):1-583. https://doi.org/10.1002/14651858.CD002098.pub2. www.cochranelibrary.com

4. Mechanic OJ, Persaud Y, Kimball AB (2020) Telehealth systems. Accessed Mar. 22, 2021. [Online]. Available: https://www.ncbi. nlm.nih.gov/books/NBK459384/

5. Tekin HC (2020) Kronik Hastaların Uzaktan İzlemine Yönelik Teletıp Platformu Telemedicine Platform for Remote
Monitoring of Chronic Patients. 22(64): 37-46. https://doi.org/ 10.21205/deufmd.2020226405

6. Sultan M, Kuluski K, Mcisaac WJ, Cafazzo JA, Seto E (2019) Turning challenges into design principles : telemonitoring systems for patients with multiple chronic conditions. Health Informatics J 25(4). https://doi.org/10.1177/1460458217749882.

7. Wootton R (2006) Realtime telemedicine. J Telemed Telecare 12(7):328-336. https://doi.org/10.1258/135763306778682387

8. Bray F, Ferlay J, Soerjomataram I, Siegel RL, Torre LA, Jemal A (2018) Global cancer statistics 2018: GLOBOCAN estimates of incidence and mortality worldwide for 36 cancers in 185 countries. CA Cancer J Clin 68(6):394-424. https://doi.org/10. 3322/caac. 21492

9. Yoo B-K, Kim M, Sasaki T, Melnikow J, Marcin JP (2016) Economic evaluation of telemedicine for patients in ICUs*. Crit Care Med 44(2):265-274. https://doi.org/10.1097/CCM.00000 00000001426

10. Hernandez Silva E, Lawler S, Langbecker D (2019) The effectiveness of mHealth for self-management in improving pain, psychological distress, fatigue, and sleep in cancer survivors: a systematic review. J Cancer Surviv 13(1): 97-107. Springer New York LLC. https://doi.org/10.1007/s11764-018-0730-8

11. Donnem T et al (2012) Bridging the distance: a prospective tele-oncology study in Northern Norway. Support Care Cancer 20(9): 2097-2103. Support Care Cancer. https://doi.org/10. 1007/s00520-011-1319-1

12. Spear KL, Auinger P, Simone R, RayDorsey E, Francis J (2019) Patient views on telemedicine for Parkinson disease. J Parkinsons Dis 9(2):401-404. https://doi.org/10.3233/JPD-181557

13. Søreide $\mathrm{K}$ et al (2020) Immediate and long-term impact of the COVID-19 pandemic on delivery of surgical services. https:// doi.org/10.1002/bjs.11670

14. Kretchy IA, Asiedu-Danso M, Kretchy JP (2021) Medication management and adherence during the COVID-19 pandemic: perspectives and experiences from low-and middle-income countries. Res Soc Adm Pharm 17(1):2023-2026. https://doi. org/10.1016/j.sapharm.2020.04.007

15. A. Kichloo et al (2020) Telemedicine, the current COVID19 pandemic and the future: a narrative review and perspectives moving forward in the USA. Fam Med Community Health 8(3): 530. NLM (Medline). https://doi.org/10.1136/ fmch-2020-000530

16. Mann DM, Chen J, Chunara R, Testa PA, Nov O, Mann D COVID-19 transforms health care through telemedicine: evidence from the field. https://doi.org/10.1093/jamia/ocaa072

17. Tibbi Onkologlar'ın Teletıp ile Yapılan Vizitler Hakkındaki Görüş ve Tecrübelerinin Değerlendirilmesi Anketi. https://docs. google.com/forms/d/e/1FAIpQLScP8CFYoBz3RhrSGG7c2tmk AQx86uCsaSECN-7gqT90oZ9EWg/viewform?vc $=0 \& \mathrm{c}=0 \& \mathrm{w}=1$. Accessed Sep. 20, 2020

18. Allen A, Hayes J, Sadasivan R, Williamson SK, Wittman C (1995) A pilot study of the physician acceptance of tele-oncology. J Telemed Telecare 1(1):34-37. https://doi.org/10.1177/1357633X95 00100107

19. Acharya R, Rai J (2016) Evaluation of patient and doctor perception toward the use of telemedicine in Apollo Tele Health Services, India. J Fam Med Prim Care 5(4):798. https://doi.org/10. 4103/2249-4863.201174

20. Brown W, Schmitz T, Scott DM, Friesner D (2017) Is telehealth right for your practice and your patients with asthma? J Patient Exp 4(1):46-49. https://doi.org/10.1177/2374373516685952

21. Roine R, Ohinmaa A, Hailey D (2001) Assessing telemedicine: a systematic review of the literature. CMAJ 165(6):765-771. https://doi.org/10.1136/bmj.323.7312.557

22. Lipsedge M, Summerfield AB, Ball C, Watson JP (1990) Digitised video and the care of outpatients with cancer. Eur J Cancer Clin 
Oncol 26(10):1025-1026. https://doi.org/10.1016/0277-5379(90) 90042-R

23. Nasi G, Cucciniello M, Guerrazzi C (2015) The role of mobile technologies in health care processes: the case of cancer supportive care. J Med Internet Res 17:2. https://doi.org/10.2196/jmir. 3757

24. Vidaurre $\mathrm{T}$ et al (2019) Implementation of a telechemotherapy module in the Peruvian jungle with adequate quality of life: breaking the access gaps to health with teleoncology. J Cancer Ther 10(08):677-691. https://doi.org/10.4236/jct.2019.108056

25. Chan BA, Larkins SL, Evans R, Watt K, Sabesan S Do teleoncology models of care enable safe delivery of chemotherapy in rural towns? Med J Aust. https://doi.org/10.5694/mja15.00190

26. Marshall L et al (2014) Implementation of a regional virtual tumor board: a prospective study evaluating feasibility and provider acceptance. Telemed e-Health 20(8):705-711. https://doi.org/10. $1089 /$ tmj.2013.0320

27. 50 Video conferencing statistics you must know For 2020। Reelnreel. https://www.reelnreel.com/video-conferencing-statistics/. Accessed Mar. 27, 2021

28. Russo JE, McCool RR, Davies L (2016) VA telemedicine: an analysis of cost and time savings. Telemed e-Health 22(3):209-215. https://doi.org/10.1089/tmj.2015.0055

29. Krijgsman J, Peeters J, Burghouts A, Brabers A, de JJ, Beenkens F (2014) Op naar meerwaarde! eHealth-monitor. Den Haag and Utrecht, The Netherlands: Nictiz and het NIVEL. 9789082030419
30. Luna R, Rhine E, Myhra M, Sullivan R, Kruse CS (2016) Cyber threats to health information systems: a systematic review. Technol Heal Care 24(1):1-9. https://doi.org/10.3233/THC-151102

31. Kruse CS, Krowski N, Rodriguez B, Tran L, Vela J, Brooks M (2017) Telehealth and patient satisfaction: a systematic review and narrative analysis. BMJ Open 7(8): e016242. BMJ Publishing Group. https://doi.org/10.1136/bmjopen-2017-016242

32. Børøsund E, Cvancarova M, Moore SM, Ekstedt M, Ruland CM (2014) Comparing effects in regular practice of e-communication and web-based self-management support among breast cancer patients: preliminary results from a randomized controlled trial. J Med Internet Res 16(12). https://doi.org/10.2196/jmir.3348

33. Le D-N, Van Le C, Tromp JG (2018) Emerging technologies for health and medicine: virtual reality, augmented reality, artificial intelligence, internet of things, robotics, industry 4.0. Wiley, New York

Publisher's note Springer Nature remains neutral with regard to jurisdictional claims in published maps and institutional affiliations. 